\title{
Multiple cropping of maize and soya beans under a high level of crop management
}

\author{
W. C. Beets ${ }^{1}$ \\ University of Rhodesia, Faculty of Agriculture, Salisbury, Rhodesia
}

Accepted: 15 March 1977

Key words: Multiple cropping; mixed cropping; maize; soya beans; cropping systems

\section{Summary}

Intercropping maize with soya beans, in different spatial arrangements reduced the grain yields per unit area of both crops. Maize alone with optimal plant populations produced the maximum yield of grain and energy, whereas associations of maize and soya beans produced maximum total fat, protein, and methionine yields. Associations used the land more intensively and land equivalent ratios of all intercropping systems were higher than of monocultures of maize and soya beans. Different ways of evaluating mixed cropping trials are discussed.

\section{Introduction}

Under natural conditions, without interference of man, plant communities of a few or one species only are rarely found. Multiple cropping, the growing of more than one crop simultaneously (intercropping) or sequentially (relay-cropping and double cropping) on the same land, is not a direct product of a formal scientific process, but an age-old farming practice in Africa, Asia and some parts of Latin America. Modern concepts of multiple cropping are however new. Presently, research is being conducted to evaluate multiple cropping patterns and systems in countries such as the Philippines, Taiwan, Nigeria, Rhodesia and Columbia.

Normally, the objective is to achieve optimum ultilization of the farmers' resources with the application of modern technology. Often emphasis is put on mixed cropping or intercropping systems. Intercropping a non-legume (often a cereal) with a leguminous crop has been the most common traditional practice of peasant farmers. It has often been observed that the yields of both crops of the association are reduced when intercropped, compared with yields when the crops are grown alone; however, the combined yield may be higher than that of the highest-yielding crop. It appears that the yield of legumes is usually more depressed

${ }^{1}$ Correspondence address: Bickerstraat 2, Heerhugowaard (N.H.), the Netherlands. 
in mixed cropping than that of non-legumes (Dalal, 1974; Donald, 1963). Often a situation arises where the cereal can considered to be the dominant species and the legume the subordinate or suppressed species (Beets, 1976). However, the decrease of yields of either legumes or non-legumes grown together could be reduced by selecting crops of widely different growth habits. Maize and soya beans do have different growth habits: maize needs much nitrogen whereas soya beans fix their own nitrogen, and maize has a superficial root system whereas soya beans is a very well rooted crop. This paper reports the effects of mixed cropping of maize and soya beans on grain, fat, protein, lysine and methionine yields, intensity of land use and financial return. Two identical experiments were conducted, one at Chibero and one at Concession. In this paper the results of the Chibero trial are reported. The results of the Concession trial generally supported the results of the Chibero trial.

\section{Materials and methods}

The main design of the experiment was based on a replacement series. In these, monocultures of both crops as well as various mixtures are planted on the understanding that the sum of the relative planting frequencies (that is the number of plants of crops $a$ and $b$ in the mixture divided by the number of plants of crops $a$ and $b$ in the monoculture) is equal to 1 (treatments $\mathrm{M}, \mathrm{A}, \mathrm{E}, \mathrm{G}, \mathrm{S}$ in Table 1). Six mixed cropping treatments and one monoculture of maize and one of soya beans were planted in a randomized block design with 5 replications. For complete description of treatments, see Table 1.

The soil in which the trial was planted is derived from dolerite, and the texture is medium grained sandy clay with a $\mathrm{pH}$ varying from 5.3-5.9 $\left(\mathrm{CaCl}_{2}\right)$.

The land was ploughed in June and just before planting; $250 \mathrm{~kg} / \mathrm{ha}$ of a compound fertilizer containing $8 \% \mathrm{~N}, 14 \% \mathrm{P}_{2} \mathrm{O}_{5}, 10 \% \mathrm{~K}_{2} \mathrm{O}$ and $6.5 \%$ sulphur was broadcasted and disked into the soil. This fertilizer application gave a medium high fertility level for maize, which fertility level is high enough for soya beans, so that soil fertility could not become a limiting factor. Top dressing of maize was done as late as possible to enable the soya beans to develop before heavy vegetative growth of the maize would cause excessive overshading. For the same reason the nitrogen application was split in two. The first application was done on 25 January 1976 and the second on 7 February 1976. At each occasion $5 \mathrm{~g}$ of ammonium nitrate $(34.5 \% \mathrm{~N})$ were given per plant. On a monoculture basis this equals a total of $153 \mathrm{~kg} \mathrm{~N}$ per hectare. The crop varieties used were R.201, a white-dent threeway maize hybrid taking approximately 130 days to physiological maturity, and Rhosa for soya beans. Rhosa has a high yield potential, is very resistant to lodging and does not normally shatter. At Chibero's altitude it takes about 120 days to mature. The crops were planted in plots of $15 \mathrm{~m} \times 15 \mathrm{~m}$ with paths of $3 \mathrm{~m}$ between plots, so that a maize row on the edge of a plot could not overshade soya beans on the adjacent plot. Around the plot a strip of 60 to $130 \mathrm{~cm}$ was planted with guard-rows. The row orientation of all treatments was east-west. The maize was 'dry planted' (planted into dry soil, before the onset of the main rains) on 
Table 1. Treatments, plant populations and spatial arrangements.

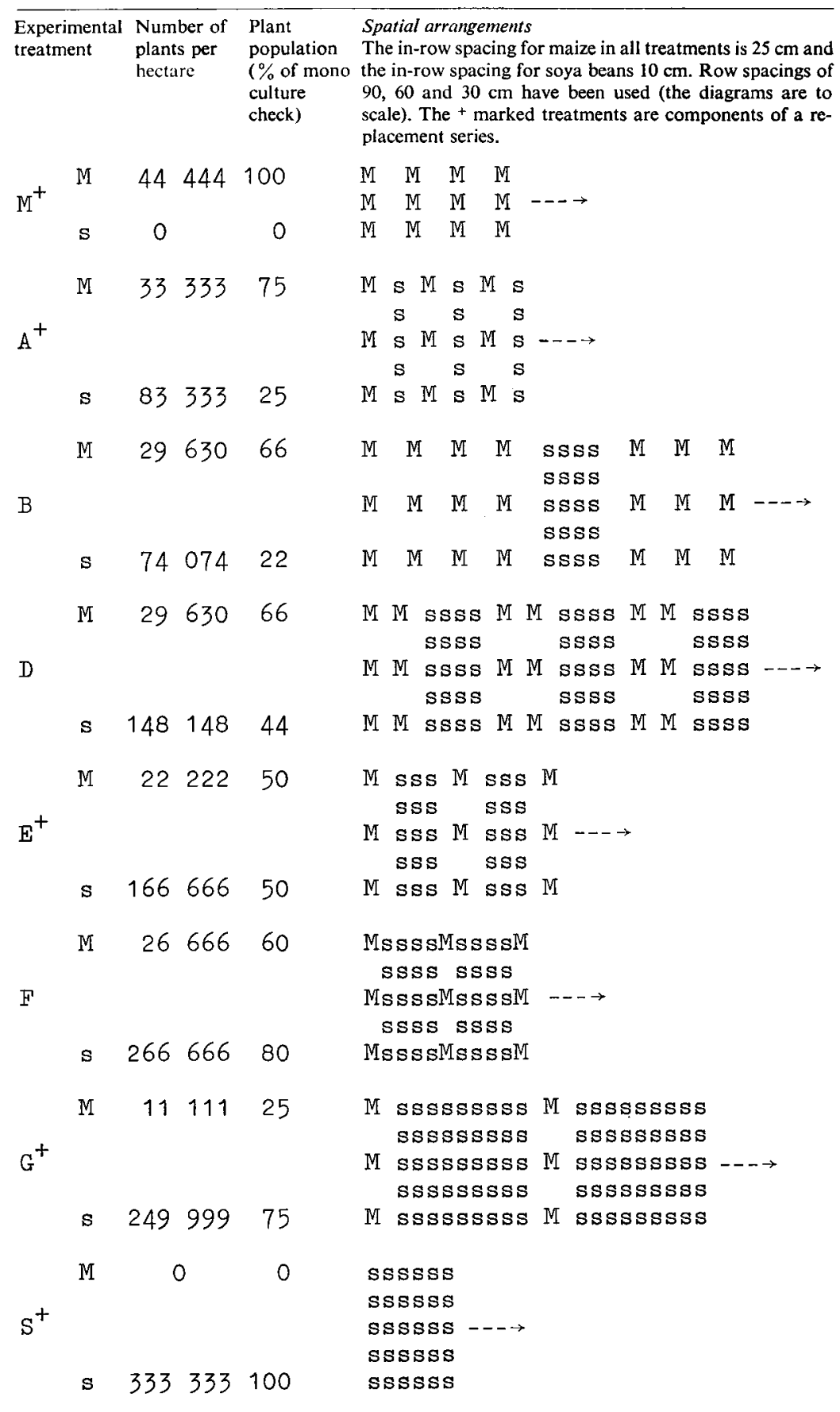

Note: $\mathrm{M}=$ maize; $\mathrm{s}=$ soya beans. 
29 November 1975. On 18 December 1975 the soya beans were planted. This difference in planting date did not give an actual difference in crop development, since the very low rainfall at the beginning of the growing period left the maize stagnant for several weeks. Hence, the vegetative development of both crops started at the same time, when the main rains started. All operations such as planting, weeding, harvesting and pest control were done by hand. Weeding of the maize rows only was done on 29 December 1975. Complete weeding (maize and soya beans) was done on 7 and 19 January 1976. Nuvacron (Monocrotophos, $490 \mathrm{ml}$ in 100 litres water) against semi-loopers (Plusia spp.) in the soya beans was sprayed on $10 \mathrm{Fe}$ bruary and 8 March 1976. Although quite a lot of soya bean leaves were eaten, it seems unlikely that the loopers reduced the leaf area to such an extend that the yield of the soya beans was reduced. The soya beans were harvested in the last week of April and the maize in the last week of May. All rows were harvested and weighed on an individual basis. The yield of each crop was calculated on the basis of the whole plot area $\left(225 \mathrm{~m}^{2}\right)$.

\section{Results}

Dry grain yields are given in Table 2. The main crop in pure stand (M) produced significantly higher yields of dry grain than all other treatments. The soya bean crop in pure stand (S) produced only 1/5 of the grain produced by the maize crop in pure stand. The yields of the pure stands as well as the yields of the mixed stands, that are components of the replacement series (treatments $A, E$ and $G$ ), are shown in Fig. 1. The dry grain yield potential of maize is much higher than the yield potential of soya beans. Therefore, the performance of the mixtures cannot be evaluated by comparing their total yields. For a better comparison of the performance of the species, the absolute yields given in Fig. 1 are converted into dimensionless relative yields (Fig. 2). The relative yield of the species is the

Table 2. Grain yield of maize and soya beans grown together at different populations and spatial arrangements, and in monocultures.

\begin{tabular}{|c|c|c|c|c|c|}
\hline \multirow[t]{2}{*}{ Treatment $^{1}$} & \multicolumn{2}{|l|}{ Maize yield } & \multicolumn{2}{|c|}{ Soya bean yield } & \multirow{2}{*}{$\begin{array}{l}\text { RYT or } \\
\text { LER }^{2}\end{array}$} \\
\hline & $\begin{array}{l}\text { in } \mathrm{kg} \text { per plot } \\
\text { (tonnes/ha) }\end{array}$ & $\begin{array}{l}\text { as fraction of mono- } \\
\text { culture check (relative } \\
\text { yields of maize) }\end{array}$ & $\begin{array}{l}\text { in kg per plot } \\
\text { (tonnes/ha) }\end{array}$ & $\begin{array}{l}\text { as fraction of mono- } \\
\text { culture check (relative } \\
\text { yields of soya beans) }\end{array}$ & \\
\hline M & $221.0(9.8)$ & 1.00 & - & - & - \\
\hline A & $163.0(7.2)$ & 0.74 & $13.9(0.6)$ & 0.29 & 1.03 \\
\hline B & $145.2(6.4)$ & 0.66 & $18.1(0.8)$ & 0.38 & 1.04 \\
\hline D & $126.7(5.5)$ & 0.57 & $21.7(1.0)$ & 0.45 & 1.02 \\
\hline E & $116.2(5.1)$ & 0.53 & $31.3(1.4)$ & 0.65 & 1.18 \\
\hline F & $117.3(5.2)$ & 0.53 & $26.9(1.2)$ & 0.56 & 1.09 \\
\hline G & $55.0(2.4)$ & 0.25 & $47.0(2.1)$ & 0.98 & 1.23 \\
\hline $\mathrm{S}$ & 一 & - & $47.8(2.1)$ & 1.00 & - \\
\hline
\end{tabular}

1 See Table 1; ${ }^{2}$ See text. 


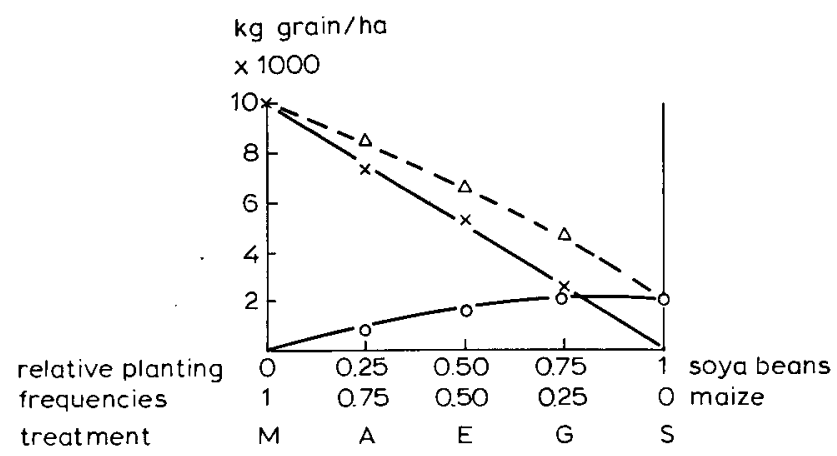

Fig. 1. Dry grain yield of maize (x) and soya beans (o) and total yields $(\triangle)$ plotted against the relative planting frequencies (see text) of treatments $M, A, E, G$ and $S$ (see Table 1).

quotient of its yield in the mixture and of its yield in the monoculture (de Wit \& van den Bergh, 1965). Hence, on a relative basis both monocultures are equal to 1 , and the mixed cultures are equal to the sum of the relative yields of the maize and the soya beans in the association (RYT $=$ relative yield total). Treatment G obtained the highest RYT, namely $0.25+0.98=1.23$ (see Table 2).

It can be concluded that an association with a relative high soya bean population is using the land most intensively. The reason for the above might be that the rows of maize plants acted as a wind break for the soya beans and changed the microclimate for the soya bean community. Since the soya beans were sheltered, the evapotranspiration of the legume could have been reduced resulting in a better water use efficiency (Radke \& Burrows, 1970). The yield per maize plant did not differ significantly (at $\mathrm{P}<0.05$ ) between treatments. Only in treatment $\mathrm{F}$ did the yield per soya bean plant differ significantly from the other treatments. The yield was lower due to heavy overshading.

Maize plant populations were kept low in all mixtures (with the exception of

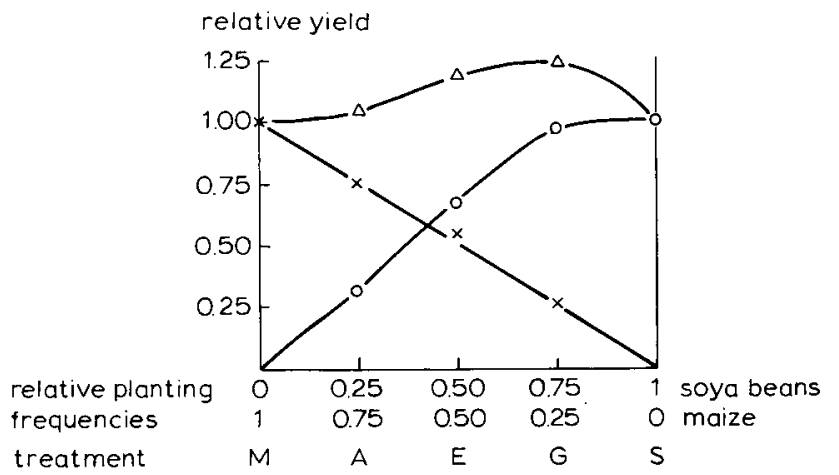

Fig. 2. Relative yields for maize (x) and soya beans (o) and relative yield totals (RYT) $(\triangle)$ plotted against the relative planting frequencies of treatments $M, A, E, G$ and $S$. 


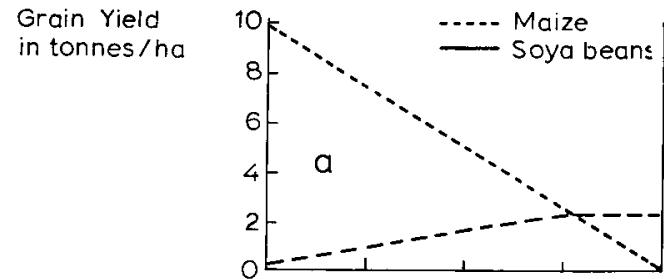

Gross income 500

in $\$$ /ha

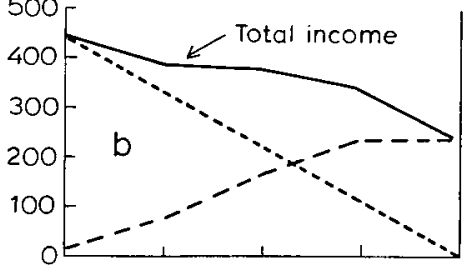

Gross Margin in $\$ / h a$
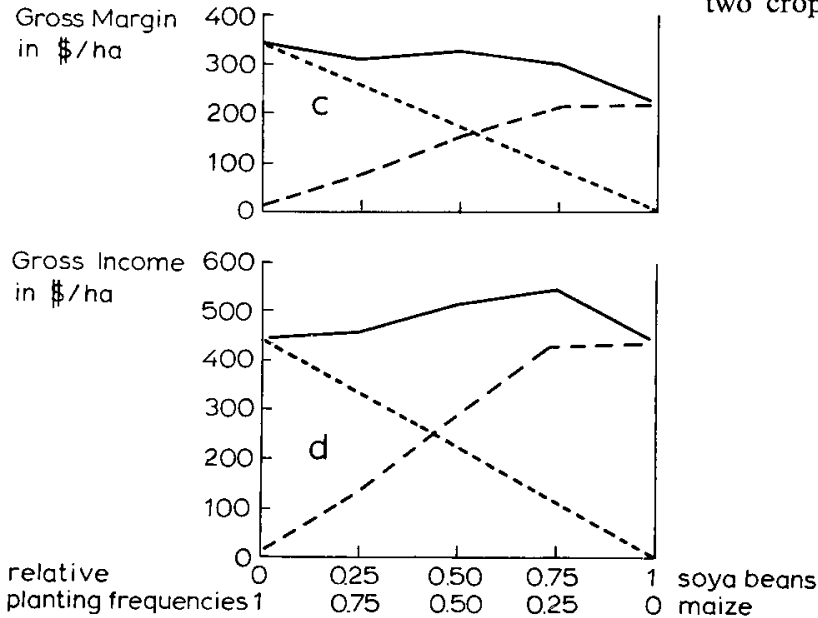

treatment $F$ ) to avoid excessive overshading of soya beans. This resulted in relatively low maize yields per unit area, but allowed the soya beans to develop normally (except in treatment F).

The optimum maize population for Chibero varies from 42000 - 48000 plants per hectare. Hence, in all mixed cultures the maize was not able to give maximum yields. The maize monoculture yield of 9.8 tonnes ha at densities of 44444 plants/ ha as well as the soya bean monoculture yield of 2.1 tonnes/ha is normal for the area.

\section{Interpretation of results}

There are several ways through which multiple cropping systems can be evaluated. Summing of the individual yields per unit area of the components of the association 
does not seem desirable since the products of the individual crops are not directly comparable. However, yields can be converted to 'relative yield total' (RYT). Table 2 gives the yields of both crops as a fraction of their respective monoculture checks and the sum of these fractions, RYT. The relative yield total is used to compare biomass of grain yields of mixtures with those of monocultures. Instead of RYT the term 'land equivalent ratio' (LER) is also used. The LER is the total land required for monocultures to give a total production of the same crop equal to that of one hectare of intercrop (Anon., 1973). The RYT and LER are identical and are given in Table 2. All LER's are $>$ I, indicating that all crop mixtures used the land more intensively than the monocultures.

Fig. 3 gives an economic evaluation of the trial results. It shows that, when prevailing crop prices are used, the growing of maize is more profitable than soya beans, or mixtures of maize and soya beans, even when the high costs of fertilizers for maize are deducted from the gross income (Fig. 3c). However, when the price of soya beans is doubled, all mixed cultures give a higher gross income than the monocultures of maize as well as of soya beans. It should be noted that in Rhodesia the cultivation of soya beans is generally not as good a commercial proposition as growing maize.

When the yields of the components of the crop association are chemically analysed, the grain yields per unit area of the two crops can be translated into the
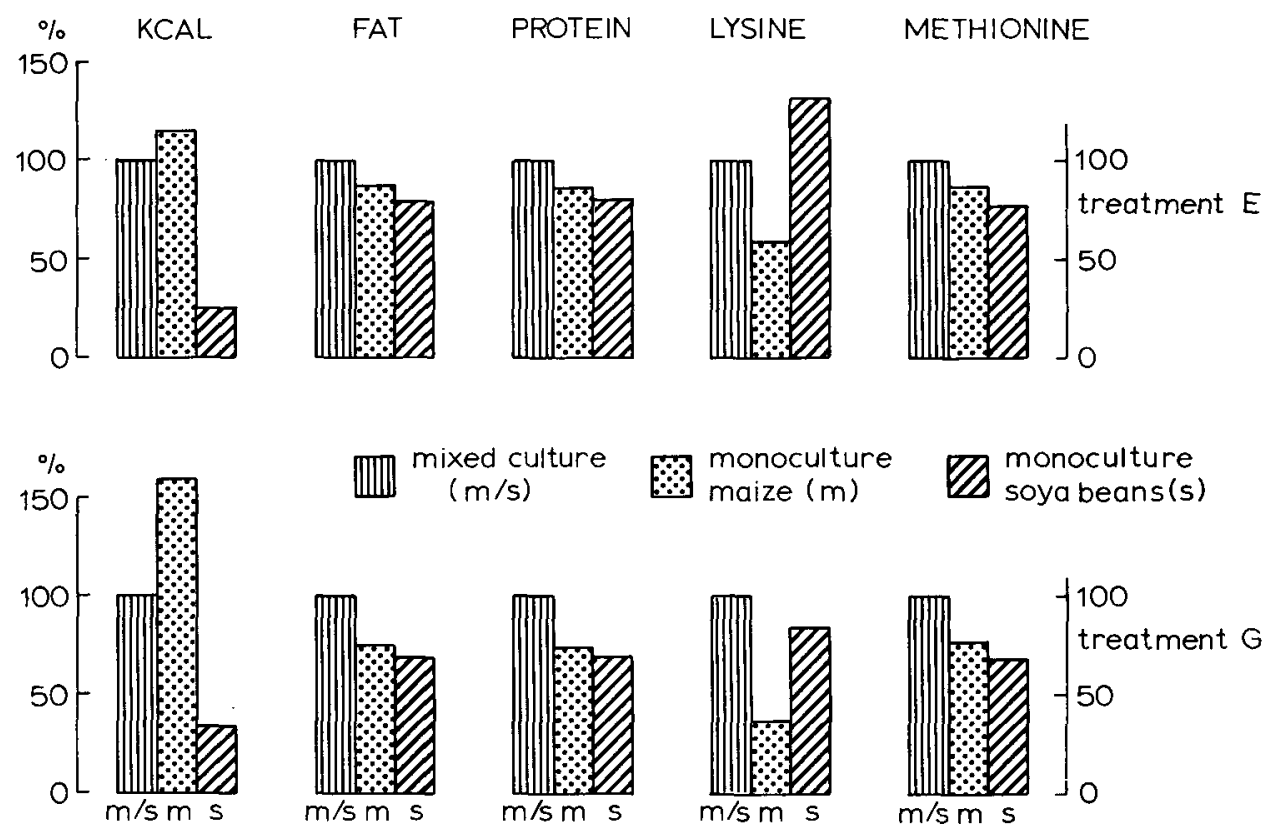

Fig. 4. Yields of the mixed cultures of treatments $\mathrm{E}$ and $\mathrm{G}(100 \%)$ compared with the monocultures in terms of energy (kcal), fat, protein, lysine and methionine. 
constituents. The constituents can be summed giving the total yield per unit area, and this is the basis on which the performance of the various crop mixtures can be compared. Fig. 4 gives the energy, fat, protein, lysine and methionine yields of the monoculture checks as a percentage of the mixtures of treatments $E$ and $G$. In terms of fat (ether extract), crude protein and methionine, the highest yield is given by the associations. In terms of lysine, the soya bean monoculture gives the highest yield, in treatment $\mathrm{E}$, but the mixed culture in treatment $\mathrm{G}$.

\section{Conclusions}

Maize alone gave the highest grain and energy yield as well as the highest economic return. However, it cannot be concluded that maize alone is always more profitable and desirable since other factors such as availability of fertilizers (maize is a high consumer, and fertilizers are scarce), nutritive value of the product and spreading of labour requirements (with mixed cultures there is more spreading) also play a role.

Evaluation of the trial in terms of intensity of land use appeared useful. This method of evaluating is commonly used and is of special importance in areas where land hunger prevails. It is in these areas that multiple cropping has a lot of scope.

Evaluation of the trial in terms of production of constituents gave interesting results. This method seems potentially very good, but presents many problems; an integrated approach requiring sophisticated techniques is necessary. The method is not commonly used in multiple cropping research.

To date, evaluating the trials in economic terms is the most common method. The chief disadvantage of this method is that the monetary values of crops are always fluctuating and also that multiple cropping systems are most common in developing areas where a cash economy sometimes does not exist.

\section{References}

Anonymous, 1973. Multiple cropping. A rep. int. Rice Res. Inst.

Beets, W. C., 1975. Multiple-cropping practices in Asia and the Far East. Agric. Envir. 2: 219-228.

Beets, W. C., 1976. Some notes on multiple cropping practices and research in this field. Paper presented at the Department of Agriculture, University of Rhodesia; $55 \mathrm{pp}$.

Dalal, R. C., 1974. Effects of intercropping maize with pigeon peas on grain yield and nutrient uptake. Expl. Agric. 10: 219-224.

Donald, C. W., 1963. On various aspects of plant competition. Adv. Agron. 15.

Radhe, J. K. \& W. C. Burrows, 1970. Soyabean plant response to temporary field windbreaks. Agron. J. 62: 424-427.

Wit, C. T. de, 1960. On competition. Versl. landbouwk. Onderz. No 668.

Wit, C. T. de \& J. P. van den Bergh, 1965. Competition between herbage plants. Neth. I. agric. Sci, 13: 212-221. 